\title{
TRES TEXTOS SOBRE LOCURA Y NORMALIDAD EN EL XIX ESPAÑOL
}

\section{R. Alvárez González}

Los textos de P. Dorado Montero, C. Bernaldo de Quirós, Tomás Maestre y J. Esquerdo son el exponente de una problemática que, entre finales del siglo xIX y principios del xx, estaba tan cadente en España como en el resto de Europa. Se trataba del reacomodo o el cambio del concepto social de normalidad y locura.

Para delimitar el marco en que se desenvuelve este cambio conceptual, expondremos sucintamente las innovaciones que sobre la definición social de locura y normalidad se producen en España, especialmente a partir de la mitad del siglo $\mathrm{XrX}$.

La definición de loco en el siglo xrx español se enmarca, en un principio, dentro de unos usos sociales dónde es el comportamiento individual el que marca la caracterización del loco. Así, un loco se reconocía socialmente como tal por su comportamiento.

Lo que hasta ahora venía siendo una frontera clara entre la locura y normalidad empieza a desdibujarse con el surguimiento de una nueva ciencia: la psiquiatría. A lo largo del siglo XIX ésta se va afianzando, alcanzando a tener importancia en España, sobre todo, a finales del siglo XIX y principios del $\mathrm{xx}^{1}$.

'Destacar que, en España, el afianzamiento de la nueva ciencia se produce sobre todo en Tribunales, siendo los médicos forenses, como posteriormente veremos, sus mejores representantes. 
La locura para esta nueva ciencia es un objeto a tratar científicamente. Mientras socialmente se había reconocido al loco por un determinado comportamiento, la ciencia intenta catalogar al loco de forma científica.

Los mentalistas españoles ${ }^{2}$ incorporan a la definición de locura dada socialmente la nueva conceptualización médica. Desde este punto de vista, el loco se convierte en un «enfermo» que los ojos de un profano no pueden reconocer. Sólo el médico frenópata estará capacitado para determinar la locura, o sea, la enfermedad mental. Este es el primer cambio que incorpora la conceptualización médica a la definición social de locura y normalidad: la locura como enfermedad mental.

Pero, cuidado, la enfermedad mental es una enfermedad orgánica, no una enfermedad del espíritu. El nuevo concepto médico de locura se enfrenta en este sentido no sólo a las tensiones de la transformación de la definición social de locura, sino también a la definición eclesiástica de bereje y endemoniado ${ }^{3}$. La Iglesia había cubierto la explicación de ciertos comportamientos como, por ejemplo, el de los epilépticos. Poseía el monopolio socialmente reconocido sobre la calificación de ciertas conductas individuales que los frenópatas trataban de convertir en enfermedades. Delimitar el campo del estudio, diferenciando la enfermedad del espíritu de la enfermedad de la mente, fue una tarea que mantuvo ocupados a muchos frenópatas españoles. De lo que supuso el enfrentamiento eclesiástico con los frenópatas, da prueba las constantes aclaraciones del doctor Esquerdo sobre tal diferenciación; así como la preocupación del frenópata por diferenciar el alma de la mente y recalcar el hecho de que su ciencia se ocupaba exclusivamente de esta última:

«Admitiendo el alma, en el sentido decadente de la actividad mental, no se puede suscribir la idea de que la locura consista en una anomalía del espíritu, pues esto equivaldría a negar la espiritualidad de dicho agente; la enfermedad mental no revela sino una alteración del instrumento cerebral...»4

Pero la locura, convertida ya en enfermedad por los frenópatas de la época, necesitaba de un agente cualitativo que la diferenciase como tal de la locura, que hasta ahora, todo el mundo podía reconocer. La innovación médica

${ }^{2}$ En España, los estudiosos de la mente reciben en el siglo xIX nombres como los de «mentalistas» o «frenópatas».

${ }^{3}$ El Código de Derecho canónico relata así uno de los impedimentos para llegar al sacerdocio: «Los que son o han sido epilépticos, amentes o poseídos del demonio...» (art. II 984.3."). La nota a pie de página nos dice: «la epilepsia, la amencia o la posesión diabólica se consideran aquí como enfermedades del espiritu, y basta que se hayan padecido, aunque no se padezca ya cuando se trata de recibir órdenes, pues suelen dejar tras de sí un rastro que difícilmente se cura».

“ Doctor J. GrNÉ, «Aforística Frenopática», en Revista Frenopática Barcelonesa, Año I, núm. III, marzo 1881, p. 12. 
a este respecto consiste en la modificación de la asociación del comportamiento a la locura.

Efectivamente, la locura médica disocia el comportamiento del individuo de la normalidad y locura de éste. Un comportamiento normal no es ya sinónimo de mente sana. De ahí que la locura médica traslade no sólo la forma de tratar la locura como una enfermedad, sino también el contenido social de ésta.

Y ¿cómo disocian los frenópatas la locura del comportamiento individual? Con el loco que no lo parece. Nuestro autores insisten en la existencia del loco razonador, del inteligente; del loco que sólo un especialista puede reconocer. Este va a ser el contenido esencial que los frenópatas van a dar a la locura.

Hemos visto el surgimiento de un concepto médico de locura sobre la definición social de ésta. Y cómo los frenópatas son protagonistas desde mitad de siglo en España del corrimiento de los límites sociales de la normalidad y la locura. Es la incorporación de la locura como enfermedad, y el contenido médico de ésta, lo que hace posible que dichos límites se transformen socialmente.

Pero no debemos olvidar que la incorporación del concepto médico de locura en la definición social tiene en España un escenario específico: el judicial. Y es éste el escenario, porque son fundamentalmente los médicos forenses los partidarios de la nueva ciencia ${ }^{5}$, los que propagan las nuevas teorías frenopáticas desde los estrados. Ellos son protagonistas de lo que, a finales del siglo XIX y principios del $\mathrm{xx}, \mathrm{R}$. Salillas denominaría «la campaña forense» en relación a las teorías mentalistas ${ }^{6}$.

Para que esta campaña pudiera llevarse a cabo por los mentalistas españoles desde los estrados de justicia, debieron unirse. dos circunstancias específicas. La primera de ellas es la de la institucionalización del peritaje médico en auxilio de la justicia ${ }^{7}$. Los informes periciales son, antes que relatos sobre el caso judicial concreto del que trata, fiel reflejo de, las nuevas teorías mentalistas (un buen ejemplo lo incluimos aquí: el informe pericial del doctor T. Maestre). En este sentido, la institucionalización de la medicina como ciencia auxiliar en el ejercicio de la justicia posibilita que los frenópatas puedan exponer sus puntos de vista en los estrados.

Pero aun así, ¿ por qué los informes periciales de los médicos podían ser

s Algunos nombres importantes son: P. Mata, J. Esquerdo, Yáñez, Simarro, Escuder, Vera. Todos ellos famosos por sus campañas forenses en famosos procesos como el de Garayo, Morillo y Galeote.

"R. Salillas, «Los locos delincuentes en España», en Revista General de Legislación y Jurisprudencia, Tomo 94, 1899, p. 124.

7 En 1855, la Ley de Sanidad crea los facultativos forenses. En 1891, un decreto reorganiza el Cuerpo Médico Forense de Madrid, creándose tres secciones: 1. Sección de Medicina y Cirugía. 2. Sección de Toxicología y Biología. 3. Sección de Medicina Mental y Antropología. Estos son dos de los puntos claves en la institucionalización del peritaje médico. 
requeridos por acusadores, defensores o magistrados para determinar la locura o no del delincuente?. ¿Por qué resultaba tan importante que éste fuera declarado loco o no?.

\section{«CAPITULO II}

De las "circunstancias" que "eximen de responsabilidad criminal"

Artículo 8. No delinquen, y, por consiguiente, están exentos de responsabilidad criminal:

1.. El imbécil y "el loco", a no ser que éste haya obrado en un intervalo de razón...»

(Código penal, promulgado en la Gaceta de 31 de agosto de 1870.)

En la exención de responsabilidad penal del loco está la clave de la significación de los informes periciales sobre el estado mental del delincuente ${ }^{8}$. Junto a ésto, constatar que la locura o enajenación no se encontraba definida jurídicamente, tratándose de lo que los juristas denominan «concepto jurídicamente indeterminado».

Hasta la llegada de los frenópatas, los jueces decidían la locura del delincuente por los usos sociales imperantes. La nueva ciencia trastoca este reconocimiento judicial y, por ende, el de responsabilidad penal. Pero, además, cuestiona la capacidad del magistrado para decidir la locura del delincuente y la de determinar su responsabilidad.

$Y$, de esta segunda cuestión, surge el conflicto entre magistrados y frenópatas. Los magistrados de la época no discuten en el fondo el tema de la locura: lo que están haciendo es defender su capacidad para determinar la responsabilidad penal del delincuente. Es de esta torma como los magistrados acaban siendo los mayores y mejores representantes de la definición social de locura a extinguir; y, como los frenópatas peritos se convierten en los mejores combatientes y representantes de la nueva definición social de locura en ascenso.

Así, aunque el enfrentamiento entre magistrados y médicos peritos sea el mejor exponente del cambio producido en España a finales del siglo XIX respecto a las definiciones sociales de normalidad y locura, no debemos olvidar, que en el fondo es un conflicto institucional en el ámbito jurídico sobre la figura de la responsabilidad penal.

Para concluir, destacaremos la incorporación de la conceptualización de la locura médica en el ámbito judicial e incluso eclesiástico; plasmándose en

${ }^{8}$ En algunas ocasiones, la declaración de locura de un delincuente podía salvarlo de la pena de muerte. 
discusiones académicas, o más o menos versadas sobre el tema, fiel exponente de una transformación tan importante como la que se estaba produciendo en la apreciación de los límites sociales de la normalidad y la locura. Después de esta transformación será «posible» «el loco que no lo parece», y que sólo el diagnóstico médico puede reconocer; los límites sociales sobre la normalidad y anormalidad se han transformado.

En fin, cada uno de los textos recogidos manifiesta desde diferentes puntos de vista, la problemática expuesta alrededor del cambio sobre el hecho social locura y sus fronteras con la normalidad. P. Dorado Montero recoge el conflicto en el ámbito judicial por el recelo de los magistrados a aceptar la nueva configuración de locura. C. Bernaldo de Quirós se muestra preocupado como hombre de ciencia por los rechazos de los magistrados a los informes periciales. Y los doctores, T. Maestre y J. Esquerdo, con sus textos, son los representantes de la nueva conceptualización médica de locura.

Para terminar, apuntaremos unos datos biográficos sobre los autores.

P. Dorado Montero (1861-1919) destaca, sobre todo, en la época por sus estudios en penología y antropología criminal. Algunas de sus obras son: La Antropología Criminal en Italia (Madrid, 1890), Asilos para bebedores (Madrid, 1901), De la criminología y la penología (Madrid, 1906), La Psicología criminal en nuestro derecho legislado (Madrid, 1910).

C. Berna'do de Quirós (1873-1962) es un reconocido sociólogo y criminólogo español. Entre sus obras destaca: Las Nuevas Teorías de la Criminalidad (Madrid 1898; ampliada en la edición inglesa de 1911), La mala vida en Madrid (Madrid, 1901), La Picota (1907), El espartaquismo andaluz (1919), Criminología del campo andaluz: cl bandolerismo (Madrid, 1934).

Tomás Maestre y Peres (1857-1923). Catedrático de Medicina Legal en la Universidad de Madrid y director del Instituto de Medicina Legal, Toxicología y Psiquiatría.

J. M. Esquerdo y Zaragoza (1842-1912). Destaca por su incansable labor en conferencias públicas y dictámenes forenses sobre la Patología Mental. Es memorable el informe del doctor Esquerdo en el caso de Garayo, apodado el Sacamantecas. Fue fundador del Manicomio de Carabanchel, donde, según las crónicas, se practicaban los más modernos tratamientos. 